\title{
sciendo
}

\section{E-learning for Business- from Covid-Adaptation to Usual Practice}

\author{
Camelia-Beatrice MAEREAN \\ Bucharest University of Economic Studies, Bucharest, Romania \\ cami.chioran@gmail.com
}

\begin{abstract}
This paper analyzes the impact of the COVID-19 epidemic on SMEs' work environment, human resources processes, how the companies reacted and adapted, what forms of support were offered by the authorities, with a particular interest for e-learning tools and systems, that may prove to not just a temporary coping mechanism, but a functional, wide-spread approach.

The scale of workforce transitions (jobs that disappeared versus jobs that opened) generated by COVID-19 on labor trends heightens the pressure for businesses and policymakers to act to support supplementary training and education programs for employees and encourages companies to address the issues related to the workforce with e-learning solutions that focus on flexibility and digitalization, as usual practice.

Consequently, the paper reviews the current options of learning management systems, aiming to support managers' decision-making process on this matter, taking into consideration infrastructure, contents, services, flexibility, and other criteria. Furthermore, the issue of implementing an e-learning project is carefully considered, in order to achieve the desired results.
\end{abstract}

Keywords: e-learning, digitalization, SMEs during COVID, sustainability, innovation.

\section{Introduction}

The COVID-19 pandemic has impacted the global economy on a scale that cannot yet be determined accurately. The lockdown and the subsequent restrictions compelled companies to reassess their business models, the processes and their calibration to the new requirements issued by the customers and the authorities.

The digital trend changed from being a competitive advantage or secondary concern to a condition for survival. New behaviors, processes and tools developed as companies had to transition to remote work, increase automation, cut back on certain activities and lines of business, increase e-commerce.

Companies are faced with complex and difficult decisions, that reshape not just their business model and processes, but also the company vision and mission, in their effort to endure this pandemic and the looming crisis.

This paper looks into the main SMEs sustainability issues brought to light by the COVID-19 pandemic, the solutions offered by various countries, the recommendations given by experts and focuses on ways to counteract the issues regarding workforce training and education through e-learning.

\section{Economic impact of COVID-19}

According to current studies, the economic crisis generated by the pandemic is second to that caused by the Second World War, with global GDP projected to reduce by $4.5 \%$ in 2020 or, in the pessimistic scenario, global economic growth would be reduced by 2 to 3 percentage points in 2021. Global unemployment would increase further and corporate invest would remain very weak (OECD, 2020). The global stock markets went through the most significant crash since 1987 (Palumbo, 2020)

DOI: $10.2478 /$ picbe-2021-0015

(C) 2021 C.-B. Maerean, published by Sciendo.

This work is licensed under the Creative Commons Attribution 4.0 License. 
On average, companies' sales declined 27 percent in October 2020 to January 2021, in respect to pre-pandemic levels, after falling 45 percent in April to September, corresponding to a recent World Bank study based on ongoing surveys with more than 120,000 companies in over 60 countries.

Other important findings of the above-mentioned report show that up to a quarter of the companies investigated had sales 50\% lower, approximately $65 \%$ of the companies changed labor expenses by reducing hors, wages or granting leave (these adjustments allowed for maintaining the workforce, with only $11 \%$ of companies having to lay off personnel). Although the trend is to adopt digital solutions, companies in poorer countries or small or small organizations are at a disadvantage from this respect $34 \%$ of the companies increased the use of internet, social media and digital platforms, while $17 \%$ invested in new equipment, software or digital solutions. Policy support is highly needed, but more is needed in poorer countries or for smaller companies $-90 \%$ of the companies in low-income countries did not receive any type of public support, while one in five companies that were not significantly affected by the pandemic were granted public support (highlighting the need for better targeting the financial aid).

Between April and June 2020, the International Labour Organization calculated that approximately 400 million full-time jobs were lost across the world (McKeever, 2020) and income earned by workers globally fell 10 percent in the first nine months of 2020, equivalent to a loss of over US\$3.5 trillion (Financial Times, 2020)

It is important to note that the economic contraction is almost uniform worldwide, with economic growth in decline in a majority of emerging and developing markets, the first instance of negative growth in at least 60 years for these countries as a group (World Bank, 2020).

\section{Governmental support for SMEs}

Governments across the world came up with various solutions to support training and skills development program for SMEs, as part of a structural policy to tackle the crisis.

According to a OECD Policy Responses to Coronavirus Study (2020), the most relevant actions to support training and redeployment for SMEs vary from free access to e-learning platforms, grants for counselling and wages subsidies that help companies maintain the workforce.

- Australia initiated a program for small companies that allows them to retain the most vulnerable workers, such as apprentices or trainees, offering a subsidy of half these employees' salary, for a period up to 9 months. Should the company not be able to retain the employee, the subsidy will be granted to the following employer that hires that person. This project is estimated to support a maximum of 70000 companies and 117000 apprentices. Another initiative is to offer mentoring, on financial issues relevant to the SMEs.

- China offers SMEs free access to e-learning platforms (Ping An Digital Economic Research Center, 2020) and grants for recruiting college graduates.

- Finland offers entrepreneurs grants amounting to 500000 euro, available for counselling or support services. Germany has a similar initiative.

- France offers partial unemployment and wage support to companies that invest in personnel training.

- Greece issued training vouchers for six scientific sectors (economists/accountants, engineers, lawyers, doctors, teachers and researchers).

- Ireland offers support for online trading of EUR 7.6 million and free mentoring, free online training for all businesses. 
- New Zealand created a NZD 100 million redeployment package, followed by a NZD 25 million fund for business consultancy support.

- Portugal dedicated a special budget to allow unemployed people to get training.

As we come across more recent assessments (OECD, World Bank), the impact of the COVID-19 crisis is estimated at larger proportions. However, it is still early to project accurate figures since the evolution of the pandemic is full of surprises.

PICBE |

\section{SMEs during COVID-19}

The various studies concur that small and medium enterprises have been suffering the hardest effects of the pandemic, due to smaller financial buffers, discriminating legal requirements (supermarkets were open while small shops had to close during lockdown, for example), less digitalization, dependency on key-workers etc.

Faced with the pandemic black swan event, the small and medium enterprises had to shift their priorities, to ensure survival (Eggers, 2020, Brown, Rocha, 2020, Osiyevskyy, Shirokova, Ritala, 2020).

Based on recent studies SMEs adopting innovative and proactive behavior can overcome the crisis and improve their performance (Kottika, Özsomer, Rydén, 2020, Beliaeva, Shirokova, Wales et al., 2020).

A main issue for the sustainability of SMEs consists in business resilience, based on product excellence, public behavior and reliability of the processes. Business resilience is aided by digital transformation - when new digital skills develop, and digital tools are implemented.

A research by García-Vidal G, Guzmán-Vilar L, Sánchez-Rodríguez A, Martínez-Vivar R, Pérez-Campdesuñer R, Uset-Ruiz F. (2020) analyzed over 100 documents published between May and June 2020, to rank the top priorities of the SMEs, with respect to the Coronavirus pandemic. The recommendations with the highest mentions regard: investment in technology, decentralize decision making, teamwork, communication across all channels, agile and flexible operations, resilience, crisis management, stakeholder management, and use of scenarios and contingency plans.

New behaviours adopted by companies during the pandemic are estimated to continue, according to a McKinsey (2021) study. Remote work: taking into consideration only remote work that can be done maintaining productivity, about 20 to 25 percent of the workforces in advanced economies could work from home between three and five days a week. This accounts four to five times more remote work than before the pandemic and could generate a large change in the geography of work, as individuals and companies move out of large cities into small cities or suburbs. However, some work that technically can be done remotely is more efficiently done in person. Negotiations, critical business decisions, brainstorming sessions, providing sensitive feedback, and onboarding new employees are examples of activities that may lose some efficacy when done remotely. E-commerce has grown 2 to 5 times faster in this period, with growth mainly in delivery, transportation, and warehouse jobs. COVID-19 may drive faster adoption of automation and AI, particularly in work areas with high physical proximity. Production figures for robotics in China exceeded pre-pandemic levels by June 2020. The mix of occupations could change, with slight job growth in the low wage occupations. The prognosis is that the largest negative impact of the pandemic will fall on workers in food service, customer sales, service roles and less-skilled office support roles. More than $50 \%$ of displaced low-wage workers will need to transfer to occupations in higher wage groups and gain different skills and competencies 
to remain employed. Companies and legislators should help facilitate workforce transitions, since $25 \%$ more workers will need to change their occupation.

The magnitude of workforce transitions generated by COVID-19's influence on labor trends heightens the pressure for businesses and policymakers to act to support supplementary training and education programs for employees. Companies and authorities proved remarkable adaptability in reacting to the pandemic with purpose and innovation so that they might help the workforce adjust to the future of work. The outcome of such efforts will be a more resilient, competent, and better-paid workforce in a more equitable society.

One of the greatest challenges consists of empowering SME owners and managers, as well as the employees, with the necessary skills to manage information and technology to connect in new ways with their customers. These skills will represent the essential competitive differentiator for their performance.

It is evident that the business sector needs to address the issues related to the workforce in a manner that focuses on flexibility and digitalization, with e-learning solutions applied as usual practice.

\section{Organizational learning}

According to Lorenz, E. and J. Potter (2019), the forms of workplace organization adopted by companies influence their capacity to innovate, and learning is associated with higher innovation in products, services and processes.

Some experts believe that organizational learning is specific to large companies, while SMEs, especially those in the commerce or service sectors do not act towards knowledge and training management regarding their employees. (Vrîncianu, Anica-Popa and Anica-Popa, 2009).

Ideally, a learning organization is described by the fact that the members permanently increase their capacity to obtain the results they really desire, and have new, broader, aspirational thinking patterns; learning is facilitated throughout the company; there is a continuous transformation and improvement process, corelated with the necessary skills for future success. Also, an organization that learns is capable of creating, acquiring and transferring knowledge, and of adapting their behavior in order to reflect the new expertise; it develops permanent improvement programs, uses systematic techniques for solving problems and transfers knowledge in a speedy and efficient manner at all the levels, through formal training programs. There are multiple definitions for organizational learning:

- a company's capacity to create, acquire, transfer, integrate knowledge and adapt behavior to improve performance (Jerez-Gomez et al., 2005);

- "Organizational learning means the process of improving actions through better knowledge and understanding." (Fiol et al, 1985);

- "An entity learns if, through its processing of information, the range of its potential behaviors is changed." (Huber, 1991);

- "Organizations are seen as learning by encoding inferences from history into routines that guide behavior." (Levitt and March, 1988);

- "Organizational learning is a process of detecting and correcting error." (Argyris, 1977);

- "Organizational learning occurs through shared insights, knowledge, and mental models...[and] builds on past knowledge and experience - that is, on memory." (Stata, 1989).

The process that allows a company to become a learning organization is complex and depends on several factors: a structure that stimulates learning, a culture oriented towards 
appreciating knowledge, a participative management style, that empowers people, internal processes and policies aiming to encourage employees to learn.

Learning organizations are skilled at five main activities: systematic problem solving, experimentation with new approaches, learning from their own experience and history, learning from the experiences and best practices of others, and transferring knowledge quickly and efficiently throughout the organization. By creating systems and processes that support these activities and integrate them into the fabric of daily operations, companies can manage their learning more effectively (Garvin, 1993).

The development of digital solutions, supported by communication speed and accessibility changed the manner in which the workforce reacts and led to a crisis related to the required skills and abilities needed to ensure companies' success in this new, interconnected economy. It is recognized that the organizational context evolves rapidly and is pressed to identify and use the most efficient and cost-effective ways to use information technology for selfdirected and life-long learning.

The evolution of technology and of the concept of learning led to new forms of education, where e-learning (a learning system that is conducted via electronic media) is the most widely used.

The concept of e-learning arrived around 1993 and provided educational content with little (if any) user tracking.

The innovative approach of e-learning for business counteracts some of the critique related to knowledge management systems, such as: complicated utilization, slow speed, maintenance issues, that frequently become obstacles for professional development, instead of facilitating this objective.

A recent and ever more popular solution is blended learning, that combines traditional learning with online alternatives. Blended or hybrid learning offers easy access, interactive learning style, cost efficiency and flexibility, if the organization's goals concerning education are correctly aligned with the teacher's and the student's learning targets.

The progress in e-learning is closely linked to the evolution of the world wide web, from a static web in $1990-2000$, to an interactive, social web, in the first decade of this century, to the current semantic web (2005 -2020), also known as web 3.0, where software agents are capable of intelligent reasoning and can produce logical solutions to user task. Semantic Web converts "display only" data to meaningful information by using meta data. (Cholai, C., 2020). In the same time, a new dimension of the web evolves, the symbiotic web, based on artificial intelligence, gains more ground. 


\section{Web Evolution}

Web 0.0

Web 1.0

Web 2.0

Web 3.0

Web 4.0
1989: The 'Web' or World Wide Web (WWW) was invented by Tim Berners-Lee 1990: Development of three fundamental web technologies: HTML, URI and HTTP 1991: First Web Browser - worldwideweb.app, webserver httpd and first website: W3 Read-only Web Static Web R $1990-2000$ Writing and Participating Web Semantic and Executing Web

Symbiotic Web

Interactive (Social)

Web

Semantic Web R-W-X

Intelligent Web ; Al
PICBE |

advanced.

In connection to the evolution of the world wide web, the e-learning system also

The second (current) generation of e-learning platforms, established after 1999, started to focus not only on the sharing of content as it also focused on the sharing of (sequences of) learning objects and learner information. The construct of these e-learning platforms became more modularized, meaning that it was easier to integrate new functions and applications. Learning administration, or course management is the focal point of these e-learning systems, rather than the learner. Some examples include WebCT/Blackboard, Moodle and SAKAI. These platforms evolved in the direction of modular architectural designs, recognizing the need for exchange.

There is a new paradigm, connected to web 3.0, named e-learning 3.0, where the semantic web offers support for course development, with supplementary resources, like new information, monitoring and evaluation, and options for customization available for the learner and the teacher, aided by intelligent solutions.

\section{E-learning solutions for business}

Worldwide, the market for educational services tailored for the business environment is estimated to have surpassed 200 billion USD. (Bersin, J., 2018). into:

In the recent years, a large number of e-learning solutions appeared, that can pe grouped

- Learning experience platforms -Degreed, EdCast, PathGather, Jam, Fuse, Cornerstone, Valamis;

- Platforms that deliver programs- Intrepid, NovoEd, EdX, Everwise, OpenEdx, Blackboard, Instructure;

- adaptive micro-learning platforms Axonify, Area 9, Grovo, Ostream, Practice, Rehearsal, Jubi, Wisetail, Echi, EduMe;

- evaluation and programming instruments oriented towards virutal reality - Lumen5, Filmora, Apple IMovie, CyberLink Power Director; 
- Content libraries- Udacity, CourseEra, EdX, Udemy, Pluralsight, Skillsoft, Crossknowledge etc;

- Instruments for digitalization and learning on the job - WalkMe, EnableNow, Microsoft Teams, Slack, GSuite;

- Learning management systems and content platforms: traditional - Saba, Success Factors, Corner Stone ; modern - Workday, Oracle, SAP, Bridge, D2L, Litmos;

- Applications for tracking learning results- Grass Blade, Learning Locker, Yet, Watershed.

After careful review of online instruments that evaluate e-learning platforms, the most important criteria SMEs should consider when choosing a learning management system are: friendly interface, user support (phone, online, data base, video), number of supported platforms, integrated instruments, functionalities, security, versatility and access from various mobile devices, calibration to the target market (freelancers, small companies, medium-sized companies), multi-media instruments and formats, instant messages, allowing collaboration, learning flexibility (synchronous or asynchronous learning), the possibility to create content, interactive evaluation and progress monitoring tools, SCORM certification and user rating. Based on these criteria, the most eligible e-learning platforms available worldwide, adequate for SMEs' needs are: Moodle, Lessonly, Docebo, Braincert, Talent LMS, Administrate, WizIQ, uQualio, SAP Litmos, Blackboard for Business.

During the COVID-19 pandemic, students all over the world had to adapt to online learning. This global experiment allowed for testing numerous platforms, applications, approaches, theories and instruments. The benefits as well as the challenges of e-learning became evident, and the advancement made with the help of the formal education field reflect on the digital education services for the business sector. As companies had to adjust their processes to social distancing and remote activities, implementing e-learning systems became a temporary solution that will probably turn into a permanent one, in a mix of educational tools.

The challenges most frequently associated with e-learning regard: difficulties in adapting to the online format (for teachers as well as for students), technical issues, computer literacy, time management, lack of interaction, security and data privacy, self-motivation.

Even the most technically advanced e-learning systems cannot make up for the engaging effect of face-to-face learning, where a gifted teacher adapts their pedagogy to the students, stimulates their curiosity and enthusiasm, perceives the aspect that are not fully understood and finds ways to correct this issue.

The use of gamification - games and rewards for reaching learning milestones - helps students maintain motivation and focus.

Also, the mix of video, text, interactive content and combining synchronous and asynchronous learning methods are substantial factors for e-learning success.

Although formal education and training used in the business environment are essentially about gaining skills, knowledge, abilities, there are some differences that corporate educational solutions must integrate. The accent on the practical side of the contents, with relevant case studies and examples, collaborative tools, efficient learning organization, progress tracking and learning goals linked with the actual job of the student are key elements for a successful elearning solution dedicated to the business sector.

In Romania, large companies use their own hybrid learning systems, based on e-learning platforms tailored to their needs and use this approach to create an attractive organizational culture, as well as a well-trained workforce. However, this option is not easily available to small and medium-sized companies, due to the costs entailed. Consequently, SMEs have to choose 
between using free e-learning platforms, subscription-based e-learning solutions, organizing internal trainings, where experienced workers teach new employees, hiring external consultants/teachers, documenting work procedures and creating a knowledge management system based on these documents, temporarily hiring specialists with the skills missing from the current team, outsourcing the activities that exceed the abilities and skills of the current workforce or, lastly, feigning competence by copying their competition.

\section{E-Learning Performance Assessment}

E-learning performance assessment can be divided into four categories: the learning and growth perspective, the business process perspective, the customer perspective, and the financial perspective. The relevant key performance indicators for each category are presented in the figure below.

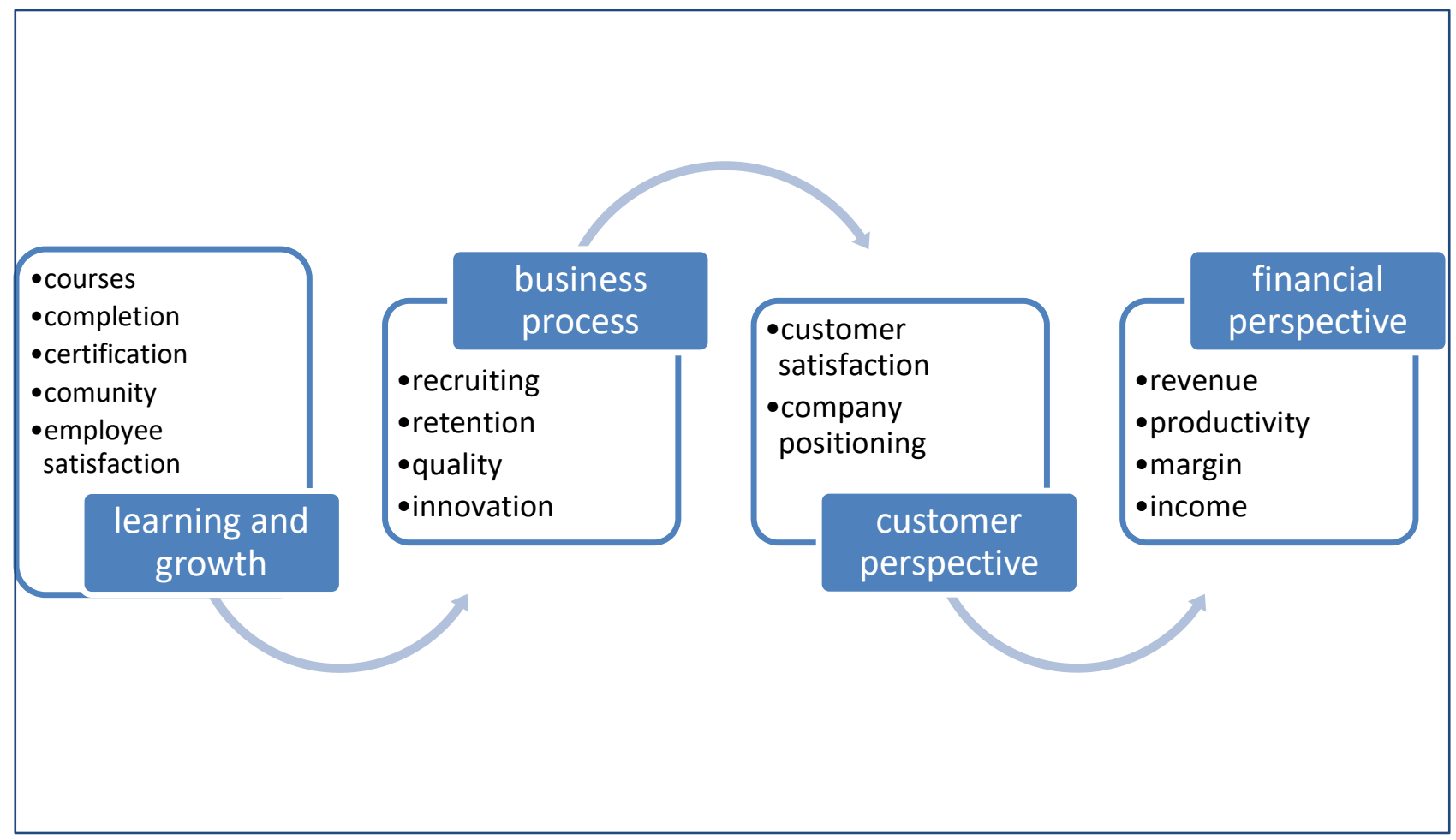

Figure 2. Performance evaluation for e-learning

Source: adaptation after Morland V., Bivens, H. (2003).

\section{Conclusion}

The COVID-19 pandemic offers vast research opportunities, in all the scientific fields, and, for at least some of the companies, this could be an incredible occasion to reinvent themselves, to rethink their priorities and to make hard, informed decisions. Both economic and social costs of transitioning the pandemic and its effects could be reduced, in our opinion, by mitigating workforce disruptions with supplementary training and education programs, through e-learning.

Although, technically, most of the top-rated e-learning solutions are very similar, the guidelines provided in this paper can help companies to choose the platform that best suits their needs, budget and organizational culture. In our opinion, the most relevant differentiator should 
be the quality of the contents and the teaching efficiency. Using the key performance indicators described, SMEs can calculate e-learning ROI and validate their decisions.

This approach would allow for a better calibration of company requirements and employees abilities and knowledge, in a customized, measurable, flexible and innovative manner.

\section{References}

Argyris, C. (1977), Organizational learning and management information systems, Accounting, Organizations and Society, 2(2), 113-123, Retrieved from https://EconPapers.repec.org/ RePEc:eee:aosoci:v:2:y:1977:i:2:p:113-123.4.

Beliaeva, T, Shirokova, G, Wales, W, et al. (2020). Benefiting from economic crisis? Strategic orientation effects, trade-offs, and configurations with resource availability on SME performance. Int Entrepren Manag J., 16(1), 165-194.

Bersin, J. (2018). A New Paradigm For Corporate Training: Learning In The Flow of Work, Insights on Corporate Talent, Learning, and HR Technology. Retrieved from https://joshbersin.com/2018/06/a-new-paradigm-for-corporate-training-learning-in-theflow-of-work/.

Brown, R., Rocha, A. (2020). Entrepreneurial uncertainty during the Covid-19 crisis: mapping the temporal dynamics of entrepreneurial finance. J Bus Ventur Insights 2020, 14: e00174.

Cholai, Carole (2020). Semantic Web: e-Learning 3.0. Retrieved from https://pngictmeri. wordpress.com/semanticweb-e-learning30/.

Dagger, D., O'Connor, A., Lawless, S., Walsh, E., \& Wade, V. P. (2007). Service-Oriented ELearning Platforms: From Monolithic Systems to Flexible Services, IEEE Internet Computing, 11(3), 28-35, https://doi.org/10.1109/MIC.2007.70.

Eggers, F. (2020). Masters of disasters? Challenges and opportunities for SMEs in times of crisis. J Bus Res 2020, 116, 199-208.

Fiol, C., \& Lyles, M. (1985). Organizational Learning. The Academy of Management Review, 10(4), 803-813. Retrieved from http://www.jstor.org/stable/258048.

García-Vidal, G, Guzmán-Vilar L, Sánchez-Rodríguez A, Martínez-Vivar R, Pérez-Campdesuñer R, Uset-Ruiz F. (2020). Facing post COVID-19 era, what is really important for Ecuadorian SMEs? International Journal of Engineering Business Management. doi:10.1177/1847979020971944.

Garvin, A.D. (1993). Building a Learning Organization, Harvard Business Review, Retrieved from https://hbr.org/1993/07/building-a-learning-organization.

Huber, G. (1991) Organizational learning: the contributing process and the literatures, Organization Science, 2(1), doi: https://www.jstor.org/stable/2634941.

Jerez-Gómez, P., Céspedes-Lorente, J., Valle-Cabrerab, R. (2005). Organizational learning capability: a proposal of measurement. Journal of Business Research, 58(6), June 2005, 715-725.

Kottika, E, Özsomer, A, Rydén, P, et al. (2020). We survived this! What managers could learn from SMEs who successfully navigated the Greek economic crisis, Ind Mark Manag, 88, 352-365.

Levitt, B., March, J. (1988). Organizational Learning, Annual Review of Sociology, 14(1), 319-338, Retrieved from https://www.annualreviews.org/action/showCitFormats?doi= 10.1146\%2Fannurev.so.14.080188.001535. 
Lorenz, E., and J. Potter (2019). Workplace organisation and innovation in small and mediumsized enterprises. OECD SME and Entrepreneurship Papers, No. 17, OECD Publishing, Paris, https://doi.org/10.1787/11732c0c-en.

McKeever, V. (2020). The coronavirus is expected to have cost 400 million jobs in the second quarter, UN labor agency estimates, Retrieved from https://www.cnbc.com/2020/06/30/ coronavirus-expected-to-cost-400-million-jobs-in-the-second-quarter.html.

McKinsey (2021). The Future of Work, Retrieved from https://www.mckinsey.com/featuredinsights/future-of-work/the-future-of-work-after-covid-19.

Morland, V., Bivens, H. (2003). E-learning in the real world, Retrieved from https://www. slideserve.com/navid/e-learning-in-the-real-world.

OECD (2020), OECD Economic Outlook, Volume 2020, Issue 1, https://doi.org/10.1787/ Od1d1e2e-en.

OECD (2020). Coronavirus (COVID-19): SME policy responses. Retrieved from https://www. oecd.org/coronavirus/policy-responses/coronavirus-covid-19-sme-policy-responses-04440 101/\#section-d1e1223.

Osiyevskyy, O, Shirokova, G, Ritala, P. (2020). Exploration and exploitation in crisis environment: implications for level and variability of firm performance. J Bus Res 2020, $114,227-239$.

Palumbo, D. (2020). Coronavirus: A visual guide to the economic impact. Retrieved from https://www.bbc.com/news/business-51706225.

Ping An Digital Economic Research Center (2020). China's SMEs Amid the Pandemic Facing cash flow problems and awaiting government aid, Retrieved from -http://www.pingan.cn/ app_upload/file/official/SMEReport2020.pdf.

Stata, R. (1989). Organizational Learning - The Key to Management Innovation. MIT Sloan Management Review. Retrieved from https://sloanreview.mit.edu/article/organizationallearning-the-key-to-management-innovation/.

The World Bank (2021). How COVID-19 is Affecting Companies Around the World. Retrieved from https://www.worldbank.org/en/news/infographic/2021/02/17/how-covid-19is-affec ting-companies-around-the-world.

Vrîncianu, M., Anica-Popa, L., \& Anica-Popa, I. (2009). Organizational Memory: an Approach from Knowledge Management and Quality Management of Organizational Learning Perspectives, Amfiteatru Economic, 11(26), 473-481. 